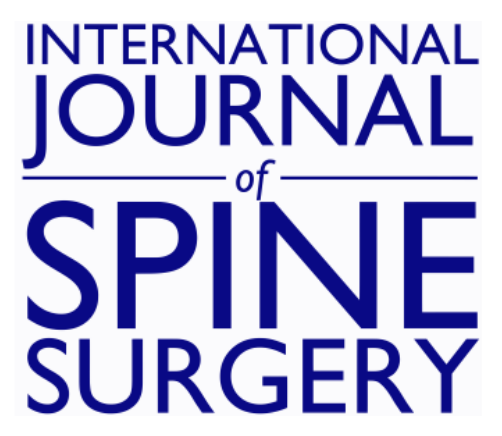

\title{
Free-hand placement of iliac screws for spinopelvic fixation based on anatomical landmarks: technical note
}

Jared Fridley, Daniel Fahim, Jovany Navarro, JP Wolinsky and Ibrahim Omeis

Int J Spine Surg 2014, 8 ()

doi: https://doi.org/10.14444/1003

http://ijssurgery.com/content/8/3

This information is current as of April 26, 2023.

Email Alerts Receive free email-alerts when new articles cite this article. Sign up at:

http://ijssurgery.com/alerts 


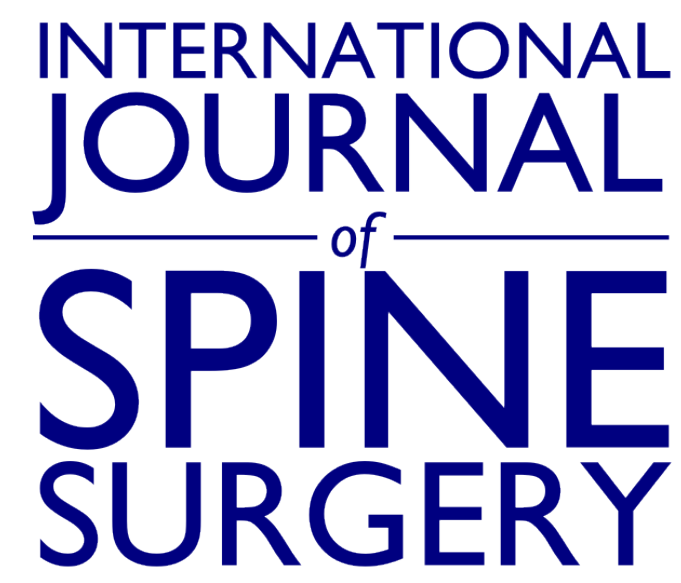

This article generously published free of charge by the International Society for the Advancement of Spine Surgery.

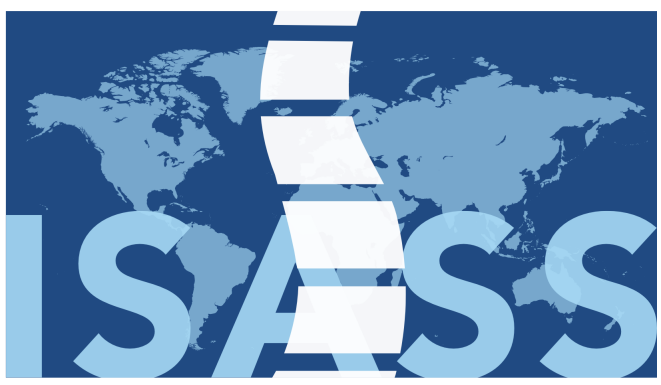

INTERNATIONAL SOCIETY for the ADVANCEMENT of SPINE SURGERY 


\section{Free-hand placement of iliac screws for spinopelvic fixation based on anatomical landmarks: technical note}

Jared Fridley, MD, ${ }^{1}$ Daniel Fahim, MD, ${ }^{1,2}$ Jovany Navarro, $M D,{ }^{1} \mathrm{JP}$ Wolinsky, MD, ${ }^{3}$ Ibrahim Omeis, $M D^{I}$

${ }^{1}$ Department of Neurosurgery, Baylor College of Medicine, Houston, TX ${ }^{2}$ Department of Neurosurgery, Oakland University William Beaumont School of Medicine, Royal Oak, MI ${ }^{3}$ Department of Neurosurgery, Johns Hopkins University School of Medicine, Baltimore, MD

\section{Abstract}

\section{Background}

The placement of iliac screws is a biomechanically sound method for the stabilization of long multi-segment lumbar constructs. Traditional techniques for the placement of iliac screws often involve either substantial iliac muscle dissection for visualization of screw trajectory based on bony landmarks, or alternatively the use of intra-operative imaging to visualize these landmarks and guide screw placement. We describe an alternative freehand method of iliac screw placement, one that needs neither significant muscle dissection nor intra-operative imaging.

\section{Methods}

We performed this technique in 10 consecutive patients. Patient demographics, spinal pathology, post-operative complications, and screw hardware characteristics are described.

\section{Results}

We have successfully used this technique for the placement 20 iliac screws based on anatomic landmarks in 10 consecutive patients. There were no cortical breeches of the ileum and no penetrations into the acetabulum on post-operative imaging. There were no instances of hardware failure. Two patients developed deep vein thromboses after surgery, 1 had a pulmonary embolism.

\section{Conclusions}

Based on our limited experience to date, free-hand placement of iliac screws is both easy to perform and safe for the patient. Further study and validation using this technique is warranted. 


\section{Introduction}

Spinopelvic fixation via the placement of iliac screws is one of the most biomechanically sound methods of stabilizing multi-segment lumbosacral constructs. These long constructs can form a lever arm that exerts significant force on the sacrum potentially causing construct failure through screw pullout or development of pseudoarthrosis. Incorporation of the ilium into the construct decreases the rate of failure. ${ }^{1}$ The first widely used surgical method that incorporated the ilium was the Galveston technique developed by Allen and Ferguson. ${ }^{2}$ This technique uses contoured rods that are inserted into each ileum at the posterior superior iliac spine (PSIS). Unfortunately the Galveston technique has a high pseudoarthrosis rate, with up to $36 \%$ seen in one study. ${ }^{3}$

Placement of iliac screws represents advancement from the Galveston technique. Iliac screw fixation has a lower pseudoarthrosis rate, and a comparably high fusion rate. ${ }^{4}$ Iliac screws are typically directed from the PSIS to the anterior inferior iliac spine (AIIS). ${ }^{5}$ Historically, surgeons who placed iliac screws often performed an extensive dissection of muscle from the ileum in order to visualize the sciatic notch, which enables better visualization of screw trajectory. ${ }^{6}$ The disadvantage of this technique is that there may be a large amount of blood loss and a possible increased risk of post-operative pain and infection.

An alternative to minimize the amount of dissection along the ilium makes use of intraoperative fluoroscopy ${ }^{7}$ or computer-assisted tomographic image guidance ${ }^{8}$ to guide screw trajectory. With these techniques direct visualization of the sciatic notch is no longer necessary, but there is added overall surgical time and an increased amount of radiation exposure.

We report the use of a novel free-hand technique for iliac screws placement based on anatomical landmarks that minimizes both the need for extensive surgical exposure of the ilium and does not require the use of intraoperative fluoroscopy for screw trajectory guidance. By utilizing this technique the overall operative time, amount of blood loss and radiation exposure can be minimized.

\section{Materials and Methods}

We have utilized free-hand placement of iliac screws in a series of 10 consecutive patients over the past year. There were 6 men and 4 women in our series. The average age was 63.2 years (range $53-74$ years). Reasons for spinopelvic fixation included patients with thoracolumbar instrumentation for degenerative scoliosis, L4-S1 pseudoarthrosis secondary to infection, and patients with lower lumbar spine metastatic lesions. Patient demographics and operative details can be found in Table 1.

Table 1. Patient demographics and surgical characteristics for 10 consecutive patients with free hand iliac screw placement over a one year period.

\begin{tabular}{|l|l|l|l|l|l|l|l|l|l|l|}
\hline Patient & Age & Sex & Pathology & $\begin{array}{l}\text { Levels } \\
\text { instrumented }\end{array}$ & $\begin{array}{l}\text { Post-op } \\
\text { complications }\end{array}$ & $\begin{array}{l}\text { EBL } \\
(\mathrm{mL})\end{array}$ & $\begin{array}{l}\text { Distance of } \\
\text { screw above } \\
\text { SN (mm) }\end{array}$ & $\begin{array}{l}\text { Diameter } \\
\text { of screw } \\
(\mathrm{mm})\end{array}$ & $\begin{array}{l}\text { Length } \\
\text { of screw } \\
(\mathrm{mm})\end{array}$ & $\begin{array}{l}\text { Acetabular } \\
\text { violation }\end{array}$ \\
\hline
\end{tabular}




\begin{tabular}{|c|c|c|c|c|c|c|c|c|c|c|}
\hline 1 & 68 & $\mathrm{~F}$ & FSI & T11-ilium & None & 700 & 20 & 8.5 & 100 & No \\
\hline 2 & 55 & M & $\begin{array}{l}\text { Osteomyelities with } \\
\text { pseudoarthosis at } \\
\text { L4-S1 }\end{array}$ & L2-IP & None & 900 & 15 & 9.5 & 110 & No \\
\hline 3 & 66 & M & DLS & T11-ilium & None & 1200 & 22 & 8.5 & 90 & No \\
\hline 4 & 65 & M & DLS & T9-ilium & PE & 850 & 13 & 8.5 & 90 & No \\
\hline 5 & 53 & M & HGS L5-S1 & L4-ilium & None & 300 & 19 & 8.5 & 100 & No \\
\hline 6 & 72 & $\mathrm{~F}$ & DLS & T11-ilium & None & 700 & 20 & 8.5 & 90 & No \\
\hline 7 & 57 & $\mathrm{~F}$ & Metastases to L5 & L2-ilium & DVT & 1000 & 22 & 8.5 & 90 & No \\
\hline 8 & 74 & $\mathrm{~F}$ & DLS & T11-ilium & None & 900 & 18 & 8.5 & 100 & No \\
\hline 9 & 59 & M & DLS & T11-ilium & None & 750 & 20 & 8.5 & 100 & No \\
\hline 10 & 63 & M & FSI & T10-ilium & DVT & 850 & 16 & 8.5 & 90 & No \\
\hline
\end{tabular}

Abbreviations: DLS = degenerative lumbar spondylisthesis; DVT = deep venous thrombosis; $\mathrm{EBL}=$ estimated blood loss; $\mathrm{F}=$ female; FSI = fixed sagittal imbalance; HGS = high grade spondylisthesis; $\mathrm{M}=$ male; $\mathrm{PE}=$ pulmonary embolism; $\mathrm{SN}$ = sciatic notch.

\section{Surgical technique}

Placement of iliac screws takes place after all other points of lumbosacral fixation are completed. We continue with subperiosteal dissection to expose the PSIS. Once the PSIS is exposed we use a Leksell rongeur to create a small recess approximately $1.5 \mathrm{~cm}$ cephalad and medial to the PSIS to accommodate the iliac screw head. This is done to prevent prominence of the screw head from the ilium which can cause significant discomfort the patient and can lead to erosion of overlying soft tissues.

To determine the trajectory for the iliac screws and create their tracts in the ilium, two gear-shift pedicle probes are angled such that their shafts are parallel to the L5 lamina, superior to inferior, with the tip of the probe pointing into the notch created in the ilium (Figure 1). The shafts of the two probes should intersect each other over the L5 spinous process making sure they are still parallel to the lamina. The trajectory that each probe takes after these steps are performed is the path that each iliac screw should take during placement, which approximates the trajectory from the PSIS to the AIIS (Figure 2). Screw length is determined based on pre-operative imaging and intra-operative probing. The screw travels above the dense cortical bone surrounding the superior aspect sciatic notch. In addition, if they are following the correct trajectory, the path of the probe will go over the L5-S1 facet joint. Each iliac screw is placed and seated such that there is no significant screw head prominence. Any connectors are attached, and then the remaining steps are undertaken for completion of the spinal construct. 


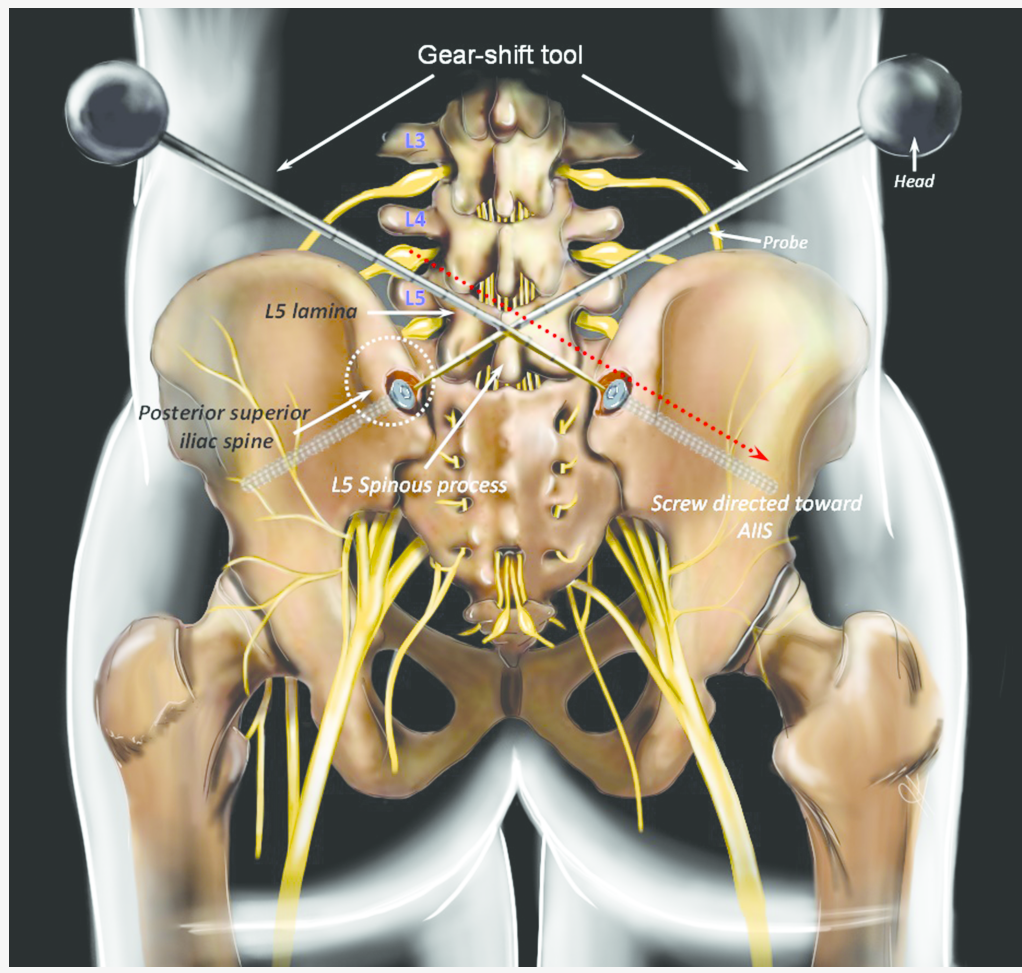

Fig. 1. Illustration of the free-hand technique for iliac screw placement. Note that the probe shafts are parallel to the L5 lamina with both probes intersecting over the L5 spinous process. The screw entry point is adjacent to the PSIS.

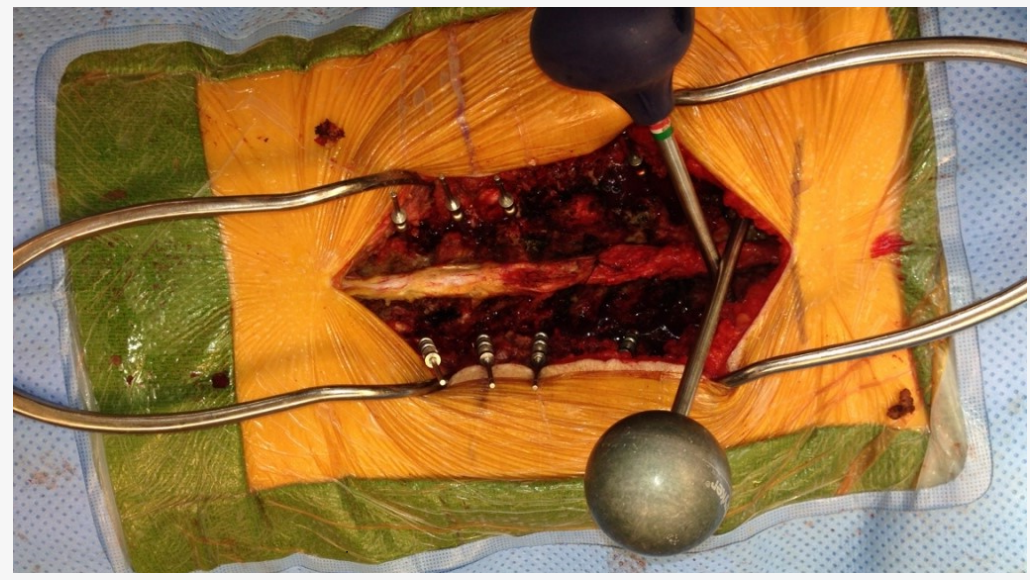

Fig. 2. Intraoperative photograph demonstrating the trajectory of both pedicle probes.

\section{Results}

A total of 20 screws were placed over a one year period in 10 patients using this free-hand technique. (Table 1) The sciatic notch was not dissected or exposed, nor was fluoroscopy used, for the placement of iliac screws in any of these cases. There were no intraoperative complications and no post-operative complications related to iliac screw placement. We evaluated the accuracy of our screw placement by measuring the shortest 
distance between the screw and the sciatic notch as well as the shortest distance to the AIIS. There were no cortical breeches of the ileum and no penetrations into the acetabulum in any of the cases. On post-operative CT scans the distances of the iliac screws above the sciatic notch ranged from 13 to $22 \mathrm{~mm}$. Screw lengths of 90-110 mm were utilized with a screw diameter of 8.5 to $9.5 \mathrm{~mm}$. Patients were seen in follow up, on average, out to 28 months after surgery (range 24 to 40 months). There were no instances of hardware failure. Two patients developed deep vein thromboses after surgery, and an additional patient developed a pulmonary embolism. An illustrative case after screw placement using post-operative CT is provided (Figure 3 ).

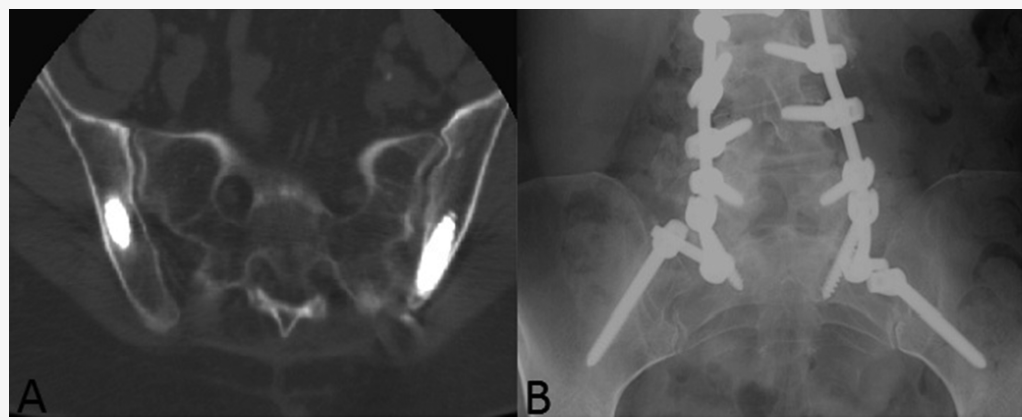

Fig. 3. a) Post-operative CT scan of lumbosacral spine, axial view, demonstrating the trajectory of the iliac screws placed through the ilium. b) anterior-posterior post-operative $\mathrm{x}$-ray illustrating a spinopelvic fixation construct.

\section{Discussion}

The first instrumented fusion technique of the lumbosacral spine was developed by Harrington in the 1960s. ${ }^{9}$ It consisted of a system of hooks and compression/distraction rods for the treatment of scoliosis. The hooks were placed under lamina or transverse processes at the most caudad and cephalad points of the construct. While relatively easy to use, the system was plagued by a high rate of pseudoarthrosis, instances of hook dislodgement, and a loss of lumbar lordosis leading to flat-back syndrome. ${ }^{10}$ The next advancement was developed by Luque ${ }^{11,12}$ who developed a system of segmental instrumentation using multiple sublaminar wires attached to ' $\mathrm{L}$ ' shaped rods. The significant advantage of the Luque system is the use of multiple fixation points. By utilizing multiple points of fixation lumbar the Luque system affords preservation of lumbar lordosis, ${ }^{13}$ avoiding flat-back syndrome.

The problem with many of these early systems was the poor ability to resist flexion and rotation forces at the lumbosacral junction. ${ }^{14}$ In the 1980s Allen and Ferguson ${ }^{2}$ developed the Galveston technique which significantly improved the ability of long constructs to withstand flexion and torsion forces at the lumbosacral junction. The major advance of this system was the incorporation of the ileum. The Galveston technique involves insertion of contoured rods into each ileum, starting at the PSIS and ending at the region in the ileum above the sciatic notch, and then attaching them to the lumbar spine. A high fusion rate and low pseudoarthrosis rate has been reported using this technique. ${ }^{15}$ 
Iliac screw placement has by and large replaced implantation of Galveston contoured rods in spinopelvic fixation. Galveston rods are more technically difficult to contour and place, 16 and iliac screw fixation offers similar rates of fusion and pseudoarthrosis ${ }^{4,17,18}$ Two trajectories are available for iliac screw placement, one aims towards the superior rim of the acetabulum and the other to the AIIS. ${ }^{5}$ Both trajectories have entry points starting at the PSIS, but the trajectory length from PSIS to AIIS is longer, which can afford insertion of longer screws. While longer screws have increased pullout strength, there may be no en vivo physiologic or functional benefit versus shorter iliac screws. ${ }^{19}$ One of the main reasons the trajectory aiming towards the AIIS is preferred is the risk of acetabular violation, ${ }^{20}$ and why we prefer to aim our screws towards the AIIS.

There are two widely practiced methods currently used to guide the trajectory of iliac screws. The goal of both of these methods is to avoid cortical breach with potential injury to adjacent neural and vascular structures. The first method involves extensive dissection of gluteal muscle and soft tissue from the ileum in order to physically palpate the sciatic notch. When inserting an iliac screw, the bony cortex is palpated to ensure no breach occurs. The second method is to radiographically guide screw placement. This can be done using intraoperative fluoroscopy or intraoperative computed tomography (CT). ${ }^{21}$ The introduction of intraoperative imaging introduces more radiation exposure to the patient, and can increase overall operative time. Our method lacks the disadvantages of both methods.

An alternative method of spinopelvic fixation is $\mathrm{S} 2$ alar iliac pelvic fixation. ${ }^{22}$ In this technique iliac screws are placed starting $1 \mathrm{~mm}$ inferior and $1 \mathrm{~mm}$ lateral to the $\mathrm{S} 1$ foramen. Screws are directed toward the greater trochanter, 30 degrees anterior from the floor. Radiographs are then used to ensure screw placement cepahlad to the sciatic notch. The deep starting point for screw insertion makes the screw heads low profile. However, this also means longer screws and more uncertainty in their trajectory necessitating additional radiographs. Furthermore, one cadaveric study found that in $60 \%$ of screws placed violation of the sacroiliac joint occurs. ${ }^{23}$ Whether or not this is clinically significant is unknown.

We believe, based on experience, that the relationship between the L5 spinous process/ laminae and the PSIS is relatively constant across the population, though further study of this relationship is needed. Additionally, care should be taken when considering this technique in the treatment of patients with high grade spondylisthesis. Although we have not yet validated our free-hand technique in this more complex patient population, we believe it is safe and effective in patients who are not at the pathological extremes of these sacro-pelvic parameters.

This is to our knowledge the first reported free-hand technique for the placement of iliac screws. Based on our results to date, free-hand placement of iliac screws is both easy to perform and safe to the patient. We encountered no serious morbidity, no evidence of cortical breeches, and the overall time required to perform this technique is significantly less than our experience with the other methods. Further study and validation using this technique is warranted. 


\section{References}

1. Lebwohl NH, Cunningham BW, Dmitriev A, et al. Biomechanical comparison of lumbosacral fixation techniques in a calf spine model. Spine (Phila Pa 1976). 2002;27:2312-20.

2. Allen BL, Jr., Ferguson RL. The Galveston technique of pelvic fixation with L-rod instrumentation of the spine. Spine (Phila Pa 1976). 1984;9:388-94.

3. Emami A, Deviren V, Berven S, Smith JA, Hu SS, Bradford DS. Outcome and complications of long fusions to the sacrum in adult spine deformity: luquegalveston, combined iliac and sacral screws, and sacral fixation. Spine (Phila Pa 1976). 2002;27:776-86.

4. Kuklo TR, Bridwell KH, Lewis SJ, et al. Minimum 2-year analysis of sacropelvic fixation and L5-S1 fusion using S1 and iliac screws. Spine (Phila Pa 1976). 2001;26:1976-83.

5. Berry JL, Stahurski T, Asher MA. Morphometry of the supra sciatic notch intrailiac implant anchor passage. Spine (Phila Pa 1976). 2001;26:E143-8.

6. Moshirfar A, Rand FF, Sponseller PD, et al. Pelvic fixation in spine surgery. Historical overview, indications, biomechanical relevance, and current techniques. J Bone Joint Surg Am. 2005;87 Suppl 2:89-106.

7. Schildhauer TA, McCulloch P, Chapman JR, Mann FA. Anatomic and radiographic considerations for placement of transiliac screws in lumbopelvic fixations. J Spinal Disord Tech. 2002;15:199-205; discussion

8. Shin JH, Hoh DJ, Kalfas IH. Iliac screw fixation using computer-assisted computer tomographic image guidance: technical note. Neurosurgery. 2012;70:16-20; discussion

9. Harrington PR. Treatment of scoliosis. Correction and internal fixation by spine instrumentation. J Bone Joint Surg Am. 1962;44-A:591-610.

10. Balderston RA, Winter RB, Moe JH, Bradford DS, Lonstein JE. Fusion to the sacrum for nonparalytic scoliosis in the adult. Spine (Phila Pa 1976). 1986;11:824-9.

11. Luque ER. Segmental spinal instrumentation for correction of scoliosis. Clin Orthop Relat Res. 1982:192-8.

12. Luque ER, Cassis N, Ramirez-Wiella G. Segmental spinal instrumentation in the treatment of fractures of the thoracolumbar spine. Spine (Phila Pa 1976).

1982;7:312-7.

13. McMaster MJ. Luque rod instrumentation in the treatment of adolescent idiopathic scoliosis. A comparative study with Harrington instrumentation. J Bone Joint Surg Br. 1991;73:982-9.

14. Ogilvie JW, Schendel M. Comparison of lumbosacral fixation devices. Clin Orthop Relat Res. 1986:120-5.

15. Saer EH, 3rd, Winter RB, Lonstein JE. Long scoliosis fusion to the sacrum in adults with nonparalytic scoliosis. An improved method. Spine (Phila Pa 1976). 1990;15:650-3.

16. Peelle MW, Lenke LG, Bridwell KH, Sides B. Comparison of pelvic fixation techniques in neuromuscular spinal deformity correction: Galveston rod versus iliac and lumbosacral screws. Spine (Phila Pa 1976). 2006;31:2392-8; discussion 9.

17. Farcy JP, Rawlins BA, Glassman SD. Technique and results of fixation to the sacrum with iliosacral screws. Spine (Phila Pa 1976). 1992;17:S190-5. 
18. Tsuchiya K, Bridwell KH, Kuklo TR, Lenke LG, Baldus C. Minimum 5-year analysis of L5-S1 fusion using sacropelvic fixation (bilateral S1 and iliac screws) for spinal deformity. Spine (Phila Pa 1976). 2006;31:303-8.

19. Zheng ZM, Yu BS, Chen H, et al. Effect of iliac screw insertion depth on the stability and strength of lumbo-iliac fixation constructs: an anatomical and biomechanical study. Spine (Phila Pa 1976). 2009;34:E565-72.

20. Santos ER, Sembrano JN, Mueller B, Polly DW. Optimizing iliac screw fixation: a biomechanical study on screw length, trajectory, and diameter. J Neurosurg Spine. 2011;14:219-25.

21. Garrido BJ, Wood KE. Navigated placement of iliac bolts: description of a new technique. Spine J. 11:331-5.

22. Matteini LE, Kebaish KM, Volk WR, Bergin PF, Yu WD, O'Brien JR. An S-2 alar iliac pelvic fixation. Technical note. Neurosurg Focus. 2010;28:E13.

23. O'Brien JR, Yu WD, Bhatnagar R, Sponseller P, Kebaish KM. An anatomic study of the S2 iliac technique for lumbopelvic screw placement. Spine (Phila Pa 1976). 2009;34:E439-42.

\section{Corresponding Author}

Ibrahim Omeis, MD, Department of Neurosurgery, Baylor College of Medicine 1709

Dryden Road, Suite 750, Houston, TX 77030.omeis@bcm.edu

\section{Disclosures}

The authors have declared no conflicts of interest.

Copyright (C) 2014 ISASS - International Society for the Advancement of Spine Surgery. To see more or order reprints or permissions, see http://ijssurgery.com. 